\title{
Immunomodulation Therapy - Clinical Relevance of Bacterial Lysates OM-85
}

\author{
Giovanni A Rossi, ${ }^{1}$ Susanna Esposito, ${ }^{2}$ Wojciech Feleszko, ${ }^{3}$ Giovanni Melioli, ${ }^{4}$ Dario Olivieri, ${ }^{5}$ Giorgio Piacentini, ${ }^{6}$ \\ Francesco Scaglione ${ }^{7}$ and Donata Vercelli ${ }^{8}$ \\ 1. Giannina Gaslini Institute, Genoa, Italy; 2. Pediatric Clinic, Department of Surgical and Biomedical Sciences, University of Perugia, \\ Perugia, Italy; 3. Medical University of Warsaw, Warsaw, Poland; 4. Humanitas University, Milan, Italy; 5. University of Parma, Parma, Italy; \\ 6. University of Verona, Verona, Italy; 7. University of Milan, Milan, Italy; 8. University of Arizona, Tucson, AZ, US
}

DOI: https://doi.org/10.17925/ERPD.2019.5.1.17

$\mathrm{R}$ espiratory tract infections (RTIS) affect children and adults with chronic respiratory conditions throughout the world. As RTIs can often recur, they confer a significant morbidity and mortality burden and represent an important unmet medical need. Studies have shown that the bacterial Iysates OM-85 can activate both innate and adaptive immune responses via maturation of gut mucosal dendritic cells, resulting in the homing of immune cells to lymphoid tissue in the lungs and subsequent antibody production. In line with these mechanistic properties, OM-85 has demonstrated clinical efficacy in preventing RTIs in several clinical studies, as well as exacerbations of various respiratory conditions such as asthma, chronic bronchitis, chronic obstructive pulmonary disease and chronic rhinosinusitis. In addition, clinical study and pharmacovigilance data show that $\mathrm{OM}-85$ is not only well tolerated in both adult and paediatric populations, but also can be used in combination with vaccines to provide additional benefits with a manageable risk profile. As such, OM-85 represents a valuable addition to the therapeutic landscape for recurrent or chronic respiratory conditions.

\section{Keywords}

Bacterial Iysates, immunomodulation therapy, OM-85

Disclosures: Giovanni A Rossi has received honoraria for his scientific support from AbbVie Inc, Chiesi Farmaceutici, Lusofarmaco and OM Pharma (a Vifor Pharma Group company). Susanna Esposito has received research grants from DMG, GlaxoSmithKline, Sanofi, OM Pharma (a Vifor Pharma Group company) and honoraria for her scientific support from AstraZeneca, MSD, Sanofi and Vifor Pharma. Wojciech Feleszko has worked as a speaker for Angellini, Bayer AG, GlaxoSmithKline, Mylan, Nutricia, Sandoz and OM Pharma (a Vifor Pharma Group company), and has received research grants from Phillips and Biomed. Giovanni Melioli is an advisor to Bruschettini SRL, Lallemand Pharma SAS, Eltek SPA and DASIT Spa and has received honoraria for scientific support from OM Pharma (a Vifor Pharma Group company) and OM Pharma (a Vifor Pharma Group company in Asia). Giorgio Piacentini has received honoraria for scientific support from Chiesi, Merck Sharp \& Dhome, Vifor Pharma, and Pediatrica. Donata Vercelli has received research grants from The National Institutes of Health, OM Pharma (a Vifor Pharma Group company), and Johnson \& Johnson. Dario Olivieri and Francesco Scaglione have no conflicts of interest to declare.

Acknowledgements: Editorial assistance was provided by Stuart Wakelin of Touch Medical Communications and funded by OM Pharma, a Vifor Pharma Group company.

Review Process: Double-blind peer review.

Compliance with Ethics: This article expresses the opinions of the authors based on the results of a review of the literature and did not involve any studies with human or animal subjects performed by any of the authors.

Authorship: All named authors meet the International Committee

of Medical Journal Editors (ICMJE) criteria for authorship of this

manuscript, take responsibility for the integrity of the work as a whole,

and have given final approval to the version to be published.

Received: 13 February 2019

Accepted: 24 June 2019

Citation: European Respiratory \& Pulmonary Diseases. 2019;5(1):17-23

Corresponding Author: Giovanni A Rossi, G Gaslini Hospital, Largo

G Gaslini 4, 16147 Genoa, Italy. E: giovannirossi@gaslini.org

Support: This article was drafted using content from an Advisory Board meeting organised by OM Pharma, a Vifor Pharma Group company. The publication of this article was supported by OM Pharma, a Vifor Pharma Group company. The views and opinions expressed are those of the authors.
Acute respiratory tract infections (RTIS) affect children and adults with chronic respiratory conditions throughout the world, and are associated with significant morbidity and mortality. ${ }^{1}$ Acute RTIs are one of the leading causes of mortality in both children and adults, with an estimated 3.5-4 million deaths per year attributed to both acute upper and lower RTIS. ${ }^{2,3}$ Recurrent RTIS are especially common in young children, affecting up to $25 \%$ of children $<1$ year of age and $18 \%$ of children $1-4$ years of age. ${ }^{1}$ Paediatric RTIS also incur substantial healthcare costs; they frequently cause complications that necessitate multiple medical visits, accounting for nearly half of all paediatric consultations in developed countries, and are among the leading causes of paediatric hospital admissions in the USA. ${ }^{1}$ Furthermore, although many RTIs have viral aetiology, they are still a leading cause of antibiotic prescriptions, thereby contributing to the development of antibiotic resistance and further increasing healthcare costs. ${ }^{1.4}$ Overall, despite the availability of healthcare in developed countries, RTIs still exert a substantial clinical and economic burden and represent a clear unmet medical need.

Prevention of RTIs can be difficult, as the risk factors are many and varied, including sociodemographic (partial immunisation, overcrowding), nutritional (malnutrition) and environmental aspects, as well as clinical risk factors, such as minor immunodeficiencies. ${ }^{5-7}$ However, the use of immunostimulants or immunomodulator therapies may provide an alternative therapeutic option that is complementary to vaccination. ${ }^{8}$

Bacterial lysates, such as OM-85, are produced by chemical or mechanical lysis of specific bacterial cultures. As such, they contain conserved pathogen-associated molecular patterns (PAMPs) for these bacteria, which have the potential to activate the cellular constituents of innate and adaptive non-specific loco-regional immune responses. ${ }^{9-12}$ This can lead to the induction of not only specific, but also non-specific loco-regional immune responses, with polyclonal production of immunoglobulins. ${ }^{10-13}$ Therefore, lysates of bacteria from the respiratory tract may provide clinical benefit in patients with recurrent RTIS, regardless of the viral or bacterial aetiology, in different 
Table 1: Summary of key bacterial lysates and their compositions

\begin{tabular}{|c|c|c|c|c|c|}
\hline OM-85* & Ismigen ${ }^{\dagger}$ & Imudon₹ & IRS-19 & Luivac $\$$ & PulmonarOM \\
\hline $\begin{array}{l}\text { Chemical lysate of } \\
21 \text { bacterial strains from } \\
8 \text { bacterial species }\end{array}$ & $\begin{array}{l}\text { Mechanical lysate of } \\
13 \text { bacterial strains from } \\
8 \text { bacterial species }\end{array}$ & $\begin{array}{l}\text { Bacterial lysate from } \\
13 \text { bacterial species }\end{array}$ & $\begin{array}{l}\text { Bacterial lysate from } \\
12 \text { bacterial species }\end{array}$ & $\begin{array}{l}\text { Bacterial lysate from } \\
7 \text { bacterial species }\end{array}$ & $\begin{array}{l}\text { Bacterial lysate from } \\
9 \text { bacterial species }\end{array}$ \\
\hline $\begin{array}{l}\text { - Streptococcus } \\
\text { pneumoniae } \\
\text { - Streptococcus pyogenes } \\
\text { - Streptococcus viridans } \\
\text { - Staphylococcus aureus } \\
\text { - Klebsiella pneumoniae } \\
\text { - Klebsiella ozoneae } \\
\text { - Moraxella catarrhalis } \\
\text { - Haemophilus influenzae }\end{array}$ & $\begin{array}{l}\text { - Streptococcus } \\
\text { pneumoniae } \\
\text { - Streptococcus pyogenes } \\
\text { - Streptococcus viridans } \\
\text { - Staphylococcus aureus } \\
\text { - Klebsiella pneumoniae } \\
\text { - Klebsiella ozoneae } \\
\text { - Moraxella catarrhalis } \\
\text { - Haemophilus influenzae }\end{array}$ & $\begin{array}{l}\text { - Lactobacillus acidophilus } \\
\text { - Lactobacillus delbrueckii } \\
\text { - Lactobacillus helveticus } \\
\text { - Lactobacillus fermentum } \\
\text { - Streptococcus pyogenes } \\
\text { - Streptococcus sangius } \\
\text { - Staphylococcus aureus } \\
\text { - Enterococcus faecium } \\
\text { - Enterococcus faecalis } \\
\text { - Klebsiella pneumoniae } \\
\text { - Fusobacterium } \\
\text { - nucleatum } \\
\text { - corynebacterium } \\
\text { - } \text { candoudodiphtheriticum } \\
\text { - Candida albicans }\end{array}$ & $\begin{array}{l}\text { - } \text { Streptococcus } \\
\text { - Stapheumoniae } \\
\text { - Neisseria subflava } \\
\text { - Neisseria perflava } \\
\text { - } \text { Klebsiella pneumoniae } \\
\text { - Moraxella catarrhalis } \\
\text { - Haemophilus influenzae } \\
\text { - } \text { Acinetobacter } \\
\text { calcoaceticus } \\
\text { - Enterococcus faecium } \\
\text { - Enterococcus faecalis } \\
\text { - Streptococcus pyogenes } \\
\text { - Streptococcus } \\
\text { dysgalactiae }\end{array}$ & $\begin{array}{l}\text { - Haemophilus influenzae } \\
\text { - Staphylococcus aureus } \\
\text { - } \text { Klebsiella pneumoniae } \\
\text { - Streptococcus pyogenes } \\
\text { - Streptococcus } \\
\text { pneumoniae } \\
\text { - Streptococcus mitis } \\
\text { - Branhamella catarrhalis }\end{array}$ & $\begin{array}{l}\text { - Diplococcus pneumoniae } \\
\text { - Haemophilus influenzae } \\
\text { - Klebsiella pneumoniae } \\
\text { - Moraxella catarrhalis } \\
\text { - Staphylococcus aureus } \\
\text { - Streptococcus agalactiae } \\
\text { - Streptococcus anginosus } \\
\text { - Streptococcus } \\
\text { dysgalactiae } \\
\text { - Streptococcus pyogenes }\end{array}$ \\
\hline
\end{tabular}

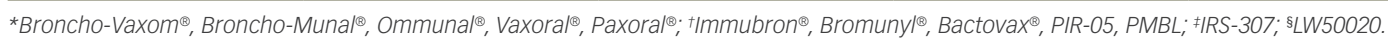

patient populations with infectious exacerbations of inflammatory respiratory conditions such as asthma and chronic obstructive pulmonary disease (COPD).

Here we discuss the concept of a bacterial lysates class effect and review the clinical relevance of the bacterial Iysates OM-85, with a focus on its efficacy and safety profile in various paediatric and adult populations.

\section{Bacterial lysates - is the class effect concept applicable?}

Pharmacological compounds are often grouped into 'classes', where each drug has similar properties or structures, and can be broadly categorised into five types based on the shared aspects: chemical, mechanistic, biomarker, outcome and genotype. The extrapolation of knowledge from one class member to another has become increasingly common; a concept known as a 'class effect'. An early example of a class effect was provided by Vaughn Williams et al., who grouped various anti-arrhythmic medications into separate classes based on their electrophysiological characteristics. ${ }^{14}$ However, while it is of practical merit to conceptualise a class effect, experience has shown that class may not always predict outcomes (e.g. there was no relationship between the Vaughan Williams anti-arrhythmic classifications and patient outcomes), ${ }^{14}$ and clinical outcomes may differ greatly for agents within a class. For example, nonsteroidal anti-inflammatory drugs have been shown to have markedly different inhibitory ratios of cyclooxygenase 1 and 2, yet a similar risk of myocardial infarction, ${ }^{15}$ and the endothelin receptor antagonists ambrisentan, bosentan, sitaxsentan and macitentan exhibit significantly different levels of hepatotoxicity (as measured by hepatic transporter inhibition and accumulation in hepatocytes). ${ }^{16}$ With regard to bacterial lysates, the concept of a class may not be applicable due to considerable variations in their composition, manufacturing process and activity/ mode of action (Table 1)..$^{10}$

Therefore, for bacterial lysates, class may not automatically translate into a class effect, and therapeutic decisions for these compounds should always be based on clinical evidence (i.e., efficacy and safety data).
An overview of the level of clinical evidence available for key bacterial lysates is provided in Table 2.

OM-85 is the product of alkaline lysis of 21 strains of eight species of common bacterial respiratory tract pathogens: Haemophilus influenzae, Streptococcus pneumoniae, Klebsiella pneumoniae, Klebsiella ozoneae, Staphylococcus aureus, Streptococcus pyogenes, Streptococcus viridans and Moraxella catarrhalis. ${ }^{10}$ The active ingredients of $\mathrm{OM}-85$ retain their activity following gastric transit, as well as their cell activation capacity following gastric-buffer incubation. ${ }^{13}$ The resultant non-specific potentiation of the immune system may help to protect against both viral and bacterial respiratory infections and, as discussed in more detail later, may also provide additional clinical benefits in inflammatory conditions such as asthma and COPD by balancing immune responses via downregulation of Th2-mediated airway hyperreactivity/inflammation and stimulating the release of anti-inflammatory cytokines. ${ }^{10,11}$

\section{OM-85 - mechanism of action}

The rationale for the use of orally administered immunomodulators for the prevention of RTIs is focused around the sampling of specific antigens by microfold (M) cells and dendritic cells in gut-associated lymphoid tissue (GALT). ${ }^{10}$ In the case of OM-85, antigen sampling by $\mathrm{M}$ cells in GALT Peyer's patches in the small intestine initiates mucosal immunity responses, allowing for transport of microbial antigens across the epithelial cell layer from the gut lumen to the lamina propria where interactions with dendritic cells can take place (Figure 1A)..$^{10-12}$ This leads to maturation of mucosal dendritic cells into antigen presenting cells, which initiate immune cascades that involves the downstream activation of cellular constituents of both the innate and adaptive branches of the immune system. 10,12 These downstream events include:

- the activation of monocytes and natural killer cells;

- the activation of T cells (T-helper [Th] 1 cells, T-regulatory [Treg] cells and cytotoxic $\mathrm{CD} 8+$ cells);

- the expression of anti-microbial peptides in epithelium and mucosa;

- the activation of macrophages;

- the migration of polymorphic neutrophils to the lung; 
Table 2: Summary of available clinical study data for key bacterial lysates

\begin{tabular}{|c|c|c|c|c|c|c|}
\hline & $\mathrm{OM}-85^{*}$ & Ismigen ${ }^{\dagger}$ & Imudon₹ & IRS-19 & Luivac $^{\S}$ & PulmonarOM \\
\hline Clinical trials & +++ & + & $+/-$ & + & ++ & - \\
\hline Safety & +++ & + & + & + & +++ & + \\
\hline Convenience dosing in children & +++ & $+/-$ & $+/-$ & + & +++ & ++ \\
\hline Composition & +++ & +++ & +++ & +++ & ++ & ++ \\
\hline Post-marketing experience (global) & +++ & - & - & - & + & - \\
\hline EPOS recommendation ${ }^{52}$ & Grade A, level 1b & - & - & - & - & - \\
\hline 'A' quality Cochrane studies & 4 & - & - & - & - & - \\
\hline
\end{tabular}

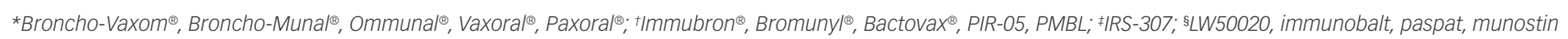
EPOS = European position paper on rhinosinusitis and nasal polyps; GOLD = global initiative for chronic obstructive lung disease.

Figure 1: Immunomodulatory mechanism of action of OM-8510

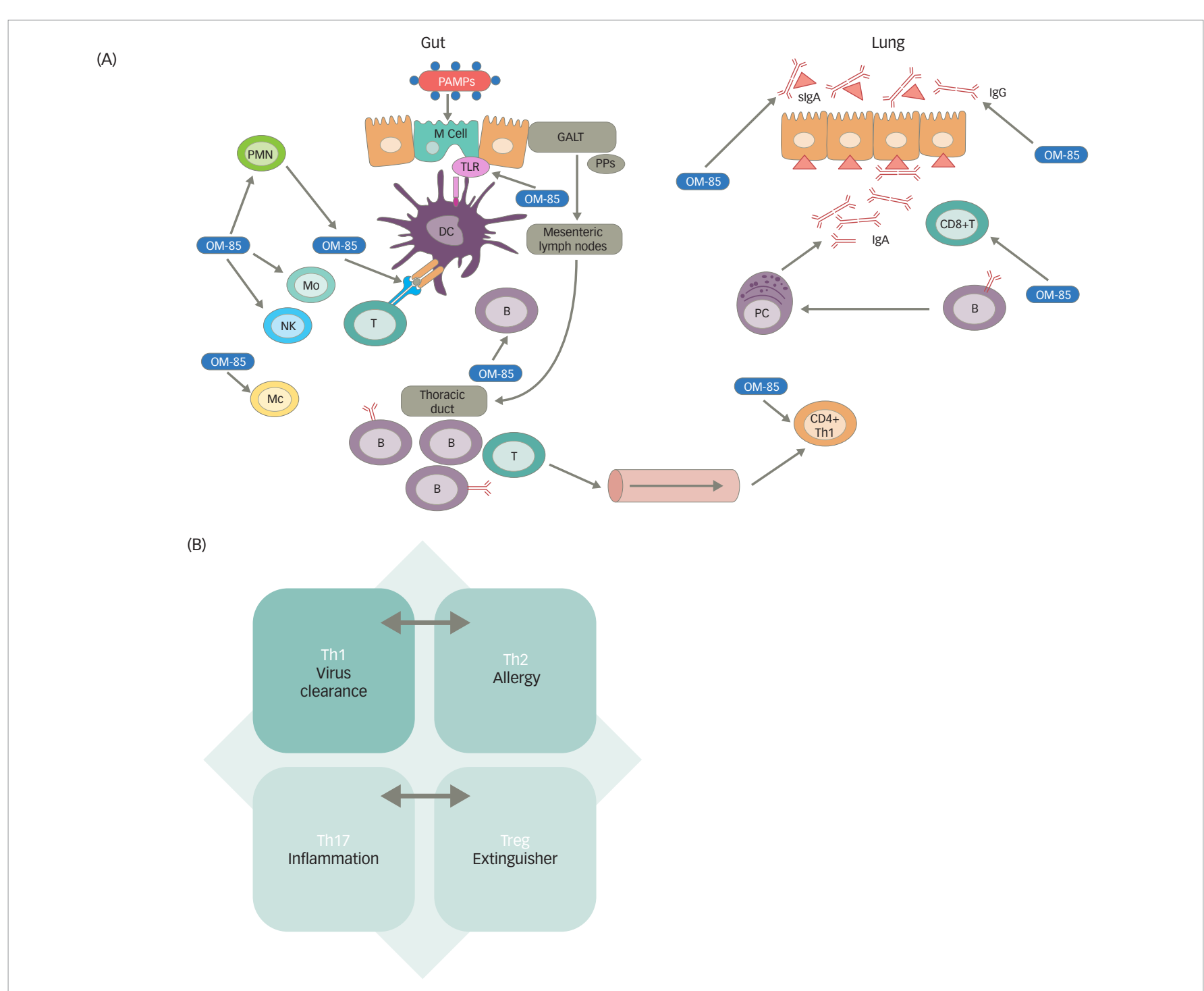

(A) OM-85 acts as a PAMP that causes maturation of mucosal dendritic cells in gut-associated immune tissue Peyer's patches (via M cells), which then cause downstream activation of cellular constituents of innate and adaptive mucosal immune responses. These downstream events include: (i) the activation of monocytes and natural killer cells; (ii) the activation of T cells (Th 1 cells, Treg cells and cytotoxic CD8+ cells); (iii) the expression of anti-microbial peptides in epithelium and mucosa; (iv) the activation of macrophages; (v) the migration of polymorphic neutrophils to the lung; (vi) the expression of B-cell and antiviral Th1-related cytokines, and (vii) B-cell maturation (leading to an increase in serum and airway immunoglobulins).

(B) OM-85 also results in the promotion of immune system maturation in children via downregulation of Th2 and restoration of Th1/Th2 imbalances through activation of Treg cells.

$B=B$ cell; $D C=$ dendritic cell; GALT = gut-associated immune tissue; $I g=$ immunoglobulin; $M C=$ macrophage; Mo = monocyte; NK = natural killer cell; $P A M P S=$ pathogenassociated molecular patterns; $P C=$ plasma cell; $P M N=$ polymorphonuclear neutrophil; $P P S=$ Peyer's patches; slg = secretory immunoglobulin; $T=T$ cell; $T h=T$ helper cell; $T L R$ = toll-like receptor; Treg $=T$ regulatory cell. 
- the expression of B-cell and antiviral Th1-related cytokines (via selective induction of nuclear factor [NF]);

- B-cell maturation (leading to an increase in serum and airway immunoglobulins); and

- the promotion of immune system maturation in children via downregulation of Th2 and restoration of Th1/Th2 imbalance through activation of Treg cells (Figure 1B). ${ }^{10-12}$

This, in turn, may result in the homing of immune cells to bronchialassociated lymphoid tissue in the lungs and subsequent polyclonal antibody production, facilitating immune responses against viral and bacterial RTIS. 10,11 In addition, OM-85 has been shown to have broader immunomodulatory effects. These include:

- an antiviral effect via the induction of interferon- $\alpha$ and interferon- $\beta$ and a dual effect on interleukin (IL)-1 production (downregulating IL$1 \beta$ during an inflammatory state, thereby controlling inflammation, but inducing pro-IL1 $\beta$ in the absence of a strong inflammatory state), indicating that OM-85 favours a protective primed immunological state while dampening inflammasome activation in specific conditions, ${ }^{-17,18}$

- the stimulation of cytokines, such as IL-6 and tumour necrosis factor-alpha (TNF- $\alpha$ ), indicating an enhanced clearance ability of macrophages against invading bacteria; ${ }^{19}$

- increasing the levels of $\mathrm{CD}^{+}, \mathrm{CD}_{2} 5^{+}, \mathrm{Foxp}^{+}$and Tregs in airway mucosal tissues, attenuating airway inflammation and hyperresponsiveness, ${ }^{20}$ and

- the selective induction of NF-к $\beta$ and MAPK in dendritic cells, thereby upregulating chemokines involved in the migration of macrophages and neutrophils, as well as upregulating B-cell activating cytokines such as IL-10, which may control excessive expression of proinflammatory mediators and tissue damage in patients with COPD. ${ }^{18}$

In summary, the effects of OM-85 have been well characterised and its mode of action is sophisticated and multifactorial, distinct from the antigen-specific action of vaccines (i.e., the production of specific antibodies by $\mathrm{B}$ cells). ${ }^{10,21}$

\section{OM-85 - safety profile}

OM-85 has a favourable safety profile that is supported by nearly 40 years of clinical experience and pharmacovigilance monitoring. ${ }^{22}$ Cumulative pharmacovigilance data from 1979 up to 31 October 2017 show that from an estimated OM-85 exposure of $~ 100$ million patients, only 1,974 adverse event reports (unsolicited and solicited) have been received and registered in the safety database (OM Pharma; data on file). From this safety database, important identified risks were shown to be limited to hypersensitivity reactions (Standardised MedDRA Query ${ }^{23}$, with 538 cases reported. The majority of these hypersensitivity reactions were classified as non-serious ( $85 \%)$ and were localised to the skin (e.g. pruritis, rash, urticaria, erythema, hypersensitivity; these accounted for $57 \%$ of all reports). In total, 28 severe adverse cutaneous reaction reports were registered in the safety database (OM Pharma; data on file), with only three instances of toxic epidermal necrolysis or StevensJohnson Syndrome reported in patients receiving OM-85 in nearly 40 years. Further, no relationship with OM-85 administration and these events was established, and therefore no safety signal was validated.

These data support the findings from placebo-controlled clinical trials, where $\mathrm{OM}-85$ has demonstrated a favourable safety profile (similar to that of placebo in most studies) in the prevention of RTIs in children, ${ }^{24,25}$ the management of atopic dermatitis in children, ${ }^{26}$ and the prevention of exacerbations in adults and the elderly with chronic lung inflammatory disease such as chronic bronchitis and/or COPD. ${ }^{27,28}$ Indeed, a meta- analysis of data from eight clinical trials investigating OM-85 for the secondary prevention of recurrent RTIS reported similar rates to placebo for minor adverse events (17.7\% versus $18.2 \%$; OM-85 versus placebo, respectively), serious adverse events (1.0\% versus $0.5 \%)$, and study withdrawals due to adverse events (1.3\% versus $0.7 \%$ ). ${ }^{29}$ No causal relationship was established for any of these adverse events, no laboratory abnormalities were reported and no deaths attributed to study medication. ${ }^{29}$

\section{Controversies - potential interference with vaccines}

There are two main concerns that have been raised regarding bacterial lysates and vaccinations: that bacterial lysates, such as OM-85, might contribute to a reduction in vaccination coverage rates, as they contain bacterial antigens such as $S$. pneumoniae and $H$. influenzae and could therefore be incorrectly regarded as a substitute for vaccines against these pathogens; and that the administration of bacterial lysates alongside vaccines may impact the immunogenicity and/or tolerability of the vaccine itself.

With regard to the potential reduction in vaccination rates, there is no robust evidence of immunostimulants or immunomodulators being prescribed as an alternative to active immunisation in Italy or other countries. Indeed, bacterial lysates are typically used to reduce the risk of respiratory infection as a complementary strategy to other preventative measures such as vaccination. ${ }^{30} \mathrm{As}$ such, the authors feel that a reduction in vaccination coverage rates due to $\mathrm{OM}-85$ use would be unlikely.

With regard to the impact on the immunogenicity and/or tolerability of vaccines, the mechanism of action of OM-85 is distinct to the antigen-specific effect of vaccines (non-specific potentiation of the immune system versus production of specific antibodies by memory $B$ cells, respectively), ${ }^{10}$ indicating that any interference is unlikely. This hypothesis is supported by the results of a prospective, randomised, single-blind study conducted by Esposito et al. of children affected by recurrent RTIS. ${ }^{31}$ In total, 68 children 36-59 months of age were vaccinated with an inactivated influenza vaccine either with $(n=33)$ or without ( $\mathrm{n}=35$ ) concomitant OM-85 (administered using a standard $3 \times 10$ dosing regimen [see clinical evidence section for further details]). ${ }^{31}$ Overall, the inactivated influenza vaccine was shown to be effective in stimulating an immune response to help prevent infection in children. ${ }^{31}$ Co-administration of the vaccine with $\mathrm{OM}-85$ was found to have no significant effect on influenza vaccine-induced seroconversion or seroprotection rates, geometric mean titres, the number of dendritic cells or the presence of plasmacytoid dendritic cells. ${ }^{31}$ In addition, OM85 did not significantly change the pool of memory B cells that produce immunoglobulin $\mathrm{G}$ and immunoglobulin $\mathrm{M}$ antibodies against influenza antigens, both of which were significantly increased post-vaccination ( $3-4$ fold increase, $p<0.01$ for both immunoglobin isotypes). ${ }^{31}$ However, compared with the administration of vaccine alone, respiratory morbidity and antibiotic use was significantly reduced in patients receiving both vaccine and $\mathrm{OM}-85$ compared with patients receiving only vaccine, suggesting an added therapeutic benefit when combining the two complementary preventive measures (Figure 2). ${ }^{31}$ The incidence of adverse events was nearly similar between the OM-85 and no OM-85 treatment groups (15.2\% versus $20.0 \%$, respectively), both for local reactions $(12.1 \%$ versus $17.1 \%)$ and systemic reactions $(6.0 \%$ versus $11.4 \%$ ), with no serious adverse events reported. ${ }^{31}$ This demonstrates the favourable tolerability profile of $\mathrm{OM}-85$ in combination with an inactivated influenza vaccine. Similar results have been reported in a study of 396 elderly patients ( $\geq 65$ years of age) receiving influenza vaccination with OM-85 $(n=147)$ or without OM-85 $(n=143) .{ }^{28}$ 
Figure 2: Effect of OM-85 on respiratory tract infections and antibiotic use in paediatric patients with or without inactivated influenza vaccine ${ }^{30}$

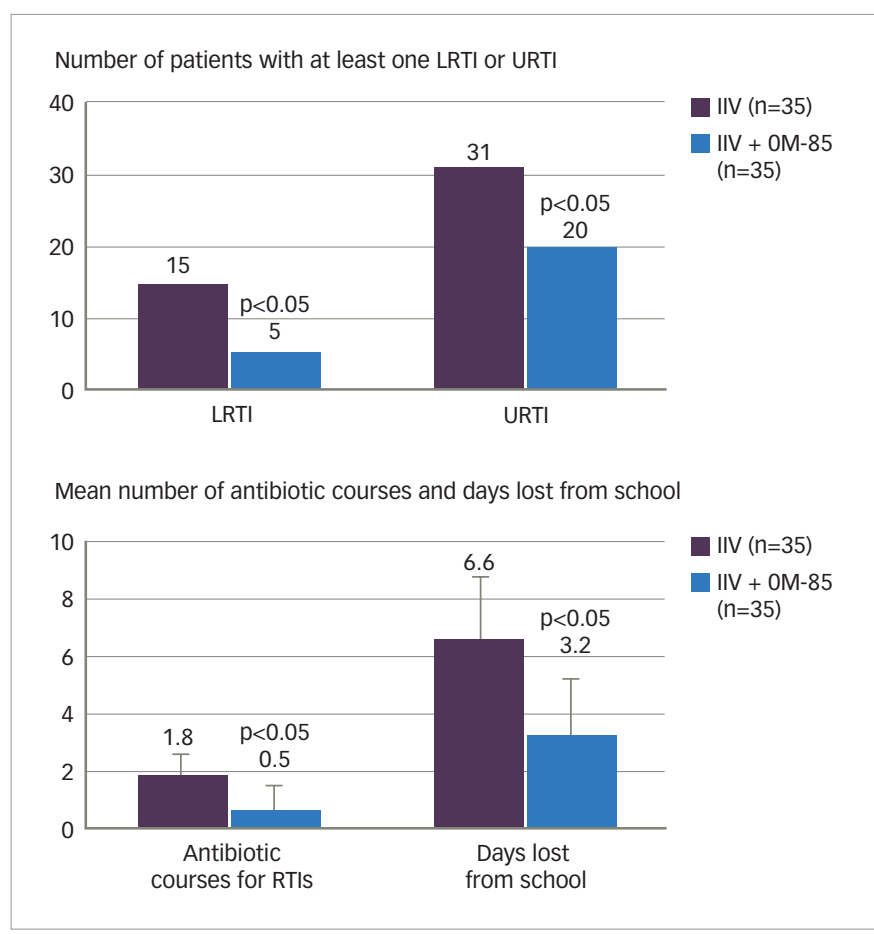

$I I V=$ inactivated influenza vaccine; $L R T I=$ Lower $R T I ; R T I=$ respiratory tract infection; URTI = upper RTI.

No significant difference between groups was observed in circulating immunoglobulin concentration or intercurrent medical events, with no specific side-effects reported. ${ }^{28}$ In addition, a $28 \%$ reduction in both lower RTIs and antibiotic use was reported with OM-85 (compared with influenza vaccination alone). ${ }^{28}$ Supporting the clinical study findings, no safety issues have been reported relating to the concomitant administration of OM-85 and influenza vaccines in post-marketing pharmacovigilance surveillance (OM Pharma; data on file; cumulative pharmacovigilance safety database from 1979 to 31 October 2017). Further, based on present general knowledge, preclinical and clinical studies, and post-marketing surveillance, there does not appear to be any evidence of interaction between $\mathrm{OM}-85$ and any vaccines, of either bacterial (e.g. Haemophilus influenzae, Streptococcus pneumoniae) or viral (e.g. trivalent or tetravalent live attenuated vaccines, such as measles, mumps, rubella and/or varicella [MMR/MMRV]) origin.

In conclusion, it is the authors' opinion that vaccination schedules for children over 12 months should not be altered when administering the bacterial lysates $\mathrm{OM}-85$, as restrictions on the concomitant use of OM-85 and vaccines (or intervals in the administration of either) are not supported by clinical evidence.

\section{Controversies - potential risks in atopic or asthmatic patients}

As described earlier, there is an established mechanistic and clinical rationale for the use of non-specific immunomodulators as prophylaxis against RTIS. 10,11 In addition, the immunoregulatory properties of OM-85 support its use in patients with an atopic condition such as poorly controlled asthma; the OM-85-induced modulation of Treg cells could potentially lead to more efficient viral clearance and a downregulation of inappropriate Th2-associated immune responses, which are central to the airway hyper- responsiveness and inflammation during asthma exacerbations. ${ }^{10,12}$ In line with this hypothesis, a number of studies have shown that prophylaxis with OM-85 in paediatric patients with a history of recurrent wheezing or asthma can significantly reduce the incidence of exacerbations triggered by infections and wheezing episodes (by 30-50\%; $p<0.05$ ), ,22-34 RTIS (by $\sim 30-40 \% ; p<0.01)$, ${ }^{32.33}$ and antibiotic use (44\% [days]; $\left.p<0.01\right) .{ }^{32}$ In addition, OM-85 was shown to have a favourable safety profile in the studies that reported safety data, with adverse events occurring at a similar incidence to placebo/control groups ( 5-10\%) and no severe events or events leading to treatment discontinuation reported. ${ }^{32,33}$

\section{Clinical evidence and relevance of $0 M-85$ in the prevention of respiratory tract infections Respiratory tract infections in the paediatric population}

Clinical study data have shown OM-85 to be effective for the prevention of RTIs in children for at least 6 months (up to $\sim 35-40 \%$ reduction) irrespective of aetiology. ${ }^{24,25,32-36}$ Additional clinical benefits have also been reported for recurrent otitis media and acute bacterial tonsillitis. ${ }^{24,35,37}$ Dosing regimens vary between these studies, but the most commonly used regimen involves administering one capsule (containing $3.5 \mathrm{mg}$ of lyophilised bacterial lysates) every morning for the first 10 days of each month for 3 months. ${ }^{29} \mathrm{~A}$ second round of $3 \times 10$ doses can also be administered 6 months after the first dose..$^{2429}$ A meta-analysis, as well as other combined study analyses, supports the results of these individual clinical trials, showing that OM-85 can significantly and consistently reduce the incidence of recurrent paediatric RTIS by $36 \%$ and that OM-85 provides the greatest benefit in preschool children and patients with a history of very frequent RTIS. 29,36,38,39 In addition, by preventing RTIS and/or bacterial complications, OM-85 has also been shown to reduce antibiotic use and provide cost-savings for the community and healthcare services..$^{40}$

Despite the burden exerted by recurrent RTIS, there are no formal international guidelines for the treatment and management of recurrent RTIs per se. In children, there are currently only guidelines for the treatment of specific paediatric conditions (such as otitis media), and while most of these recommend avoiding antibiotic overuse in the treatment of paediatric RTIs by adopting preventive measures, they do not specify what these measures might be. Clinical evidence indicates that OM-85 could address both of these issues, by reducing the frequency of RTIS and antibiotic use. ${ }^{129,36,38,40}$ Indeed, a number of expert consensus/position/opinion papers now discuss and/or recommend the use of bacterial lysates and OM-85 as effective measures for preventing RTIs in children. 1,41,42

Based on available clinical data and meta-analyses, the authors propose three key recommendations for the use of OM-85 in the prevention of recurrent RTIs in paediatric patients:

- that OM-85 is considered in children 2-6 years of age who are at the highest risk of RTIS, as OM-85 appears to confer the greatest benefit in these patients (Figure 3);

- that OM-85 is considered for the prevention of viral RTIS, as its clinical efficacy is not limited to the prevention of bacterial RTIS; and

- that the use of OM-85 is not limited by the concurrent administration of vaccines.

\section{Adult population}

COPD is a major public health challenge and a leading cause of chronic mortality and morbidity, which is predicted to become the third largest global cause of death by $2020 .{ }^{43}$ The main goals for the treatment of 
Figure 3: Illustration of the theoretical concept for the use of $\mathrm{OM}-85$ for the prevention of paediatric respiratory tract infections, based on expert opinion

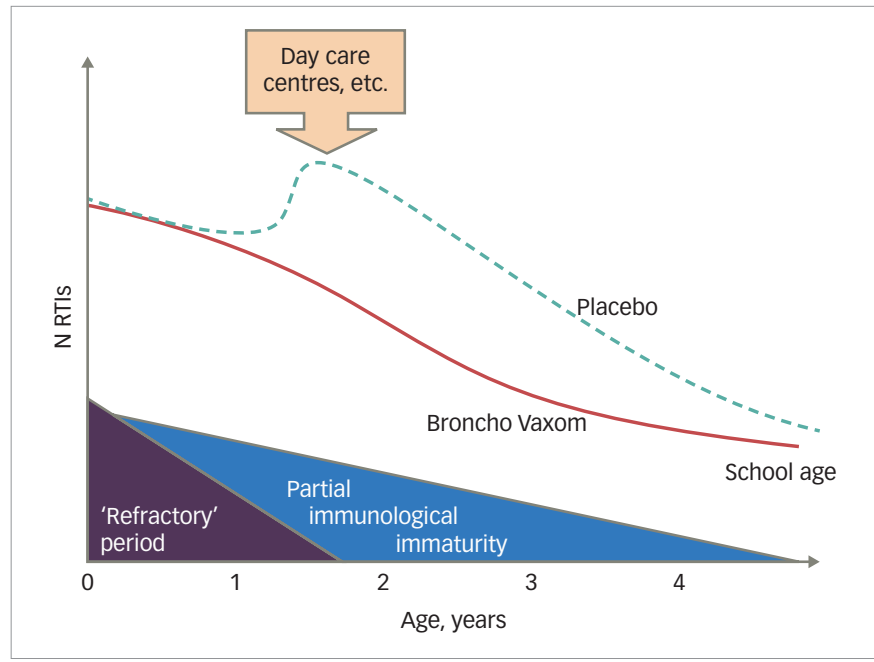

RTIS = respiratory tract infections

COPD are to reduce symptoms and prevent future exacerbations (acute episodes of disease worsening), which are associated with a worse prognosis, reduced quality of life and increased mortality risk. ${ }^{43}$ Because of the increased morbidity and mortality risk, patients with COPD who experience frequent exacerbations require additional treatment beyond symptomatic control.

As the large majority ( $50-80 \%$ ) of COPD exacerbations are associated with bacterial or viral respiratory infections, ${ }^{44}$ targeting specific molecular pathways to prevent viral/bacterial infection and reduce inflammation could therefore help prevent or mitigate COPD exacerbations. As such, OM-85 provides a complementary and effective therapeutic option for adults with COPD who experience frequent exacerbations (via modulation of the lung immune response), potentially reducing hospitalisations and the use of antibiotics. ${ }^{45}$ Data from clinical trials support this hypothesis, with several studies reporting significant reductions in exacerbations, decreased severity of exacerbations and reduced antibiotic use/ hospitalisation in patients with COPD or chronic bronchitis receiving OM-85 treatment. ${ }^{27,28,46-49}$ In addition, a meta-analysis by Pan et al. reported OM-85 to be associated with a $20 \%$ reduction in COPD exacerbations and a $39 \%$ reduction in antibiotic use. ${ }^{50}$ However, no significant effect was observed on the severity of exacerbations or duration of hospitalisations. ${ }^{50}$ Nevertheless, as healthcare costs and resource utilisation associated with COPD and other chronic respiratory conditions are high, incorporating OM-85 into an integrated care programme has the potential to reduce these costs and optimise disease management and patient outcomes. ${ }^{51,52}$ Indeed, OM-85 is included and recommended (Grade A) in treatment guidelines for acute and chronic rhinosinusitis in adults without nasal polyps, and could also provide benefits in these patients. ${ }^{53,54}$ In addition, the use of bacterial lysates is mentioned in the current Global Initiative for Chronic Obstructive Lung Disease (GOLD) document with respect to the potential benefits of reducing exacerbations in COPD. ${ }^{43}$

Overall, considering the available clinical data and meta-analyses, the key recommendations and conclusions based on author consensus are:

- that OM-85 be used in patients with COPD, as it has been associated with a reduction in exacerbations triggered by infection, and antibiotic use;
- that of these patients, OM-85 may show the greatest treatment response in those with a high frequency of exacerbations (i.e., those with the greatest risk of morbidity and mortality); and

- that OM-85 could provide a cost-effective means of reducing COPD exacerbations.

\section{Clinical relevance of $\mathrm{OM}-85$ within the context of increasing antibiotic resistance}

Antibiotic resistance is an increasing problem, with new strains of resistant bacteria continuing to emerge and $\sim 25,000$ deaths attributed to specific antibiotic resistant bacteria in the $\mathrm{EU}$ in 2007.55,56 With few alternative antibiotic options available and/or in development, there are only two viable approaches to overcome this problem: improving the use of current antibiotics and reducing the number of infections. Unfortunately, the overuse and misuse of antibiotics in paediatric patients is still a common issue despite attempts to increase awareness and education. ${ }^{4,57}$ As such, reducing the number of infections (and in turn antibiotic use) may be the most viable option. Furthermore, antibiotic treatment is an important perturbing factor of the microbial equilibrium of both the gut and respiratory microbiota throughout life. ${ }^{58}$ In children this has been shown to decrease the abundance of presumed beneficial commensal bacteria in the upper respiratory tract, which might increase the risk of RTIs following antibiotic treatment. $.^{58} \mathrm{OM}-85$ may help address these issues, as it represents a way to reduce antibiotic use, especially in patients with a higher risk of RTIS requiring antibiotics, such as those with COPD. ${ }^{28,32,40,48,50}$

Overall, the authors recommend implementation of antibiotic stewardship that includes prophylaxis with immunomodulatory agents of choice, as this may help to reduce both the appearance of antibiotic resistance and perturbations of gut and respiratory microbiota. ${ }^{58,59}$

\section{Immunomodulatory properties of OM-85 - current understanding and future perspectives}

Because immunological responses are highly complex, the targeting of multiple molecules/pathways (rather than a single molecule/pathway) is usually required in order to achieve a beneficial immunomodulatory effect. OM-85 targets multiple pathways and has a broad range of immunological effects, including Treg cell expansion in the airways. 10,60 As such, it is hypothesised that OM-85 may promote a re-organisation of gut and lung microbial communities, improving cross-talks with immune effectors that favour immune homeostasis and reducing disease exacerbations and antibiotic use..$^{58}$ However, while our understanding of microbial ecology has increased dramatically over recent years, much remains to be understood about how different microbial groups influence various arms of host immune defence, and further studies are required to characterise the effect of OM-85 treatment on these interactions. 58,61

\section{Discussion}

While OM-85 is classified as part of the bacterial lysates family, it has been shown to possess its own distinct and multifactorial mode of action, causing maturation and activation of gut mucosal dendritic cells, homing of immune cells to lymphoid tissue in the lungs and activation of cellular constituents of innate and adaptive mucosal immune responses. ${ }^{10}$

Clinical study and pharmacovigilance data have shown that OM-85 is well tolerated in both adult and paediatric populations and that it can be used in combination with vaccines with a manageable risk profile. Clinical studies have shown that OM-85 provides clinical benefits in various respiratory conditions such as asthma, chronic bronchitis, COPD and chronic rhinosinusitis, as well as clinical efficacy in preventing both 
viral and bacterial RTIs and reducing antibiotic use. Based on the evidence to date, the authors believe that OM- 85 can provide the most benefit to paediatric patients by

- considering OM-85 use in children 2-6 years of age who are at the highest risk of RTIS;

- considering OM-85 for the prevention of viral RTIs as well as bacterial RTIS; and

- not limiting the use of OM-85 during administration of vaccines. Preclinical evidence clarifying the mechanism of action of OM-85,,$^{10-12}$ together with recent clinical evidence, ${ }^{24,25,32-35}$ indicate that its use could also be extended to the prevention of recurrent paediatric infection-induced wheezing or asthma attacks, as well as providing benefits for patients with non-atopic conditions such as chronic rhinosinusitis and COPD (in adults). ${ }^{27,28,46-50,53,54}$
Overall, OM-85 represents a valuable addition to the therapeutic landscape for these conditions and may be an effective tool not only for specialists (paediatricians, pulmonologists, ear, nose and throat), but also for general practitioners.

\section{Conclusions}

In conclusion, there is growing mechanistic and clinical evidence supporting both the ability of OM-85 to promote immune homeostasis and the benefits of OM-85 therapy in various respiratory conditions such as asthma, COPD, chronic rhinosinusitis and in the prevention of RTIS. Additional research is required to further characterise the properties of OM-85 and investigate the therapeutic benefit in specific patient populations or respiratory conditions.
1. Schaad UB, Esposito S, Razi CH. Diagnosis and Management of Recurrent Respiratory Tract Infections in Children: A Practical Guide. Arch Pediatr Infect Dis. 2016;4:e31039.

2. Bosch AA, Biesbroek G, Trzcinski K et al Viral and bacterial interactions in the upper respiratory tract. PLOS Pathog. 2013;9:e1003057

3. Forum of International Respiratory Societies, The Global Impact of Respiratory Disease - Second Edition. Sheffield European Respiratory society. Available at: www.who.int/gard/ publications/The_Global_Impact_of_Respiratory_Disease.pdf (accessed 3 February 2019)

4. Vaz LE, Kleinman KP, Raebel MA, et al. Recent trends in outpatient antibiotic use in children. Pediatrics. 2014;133:375-85.

5. Savitha MR, Nandeeshwara SB, Pradeep Kumar MJ, et al. Modifiable risk factors for acute lower respiratory tract infections. Indian J Pediatr. 2007:74:477-82.

6. Fazekas T, Eickhoff P, Rauch M, et al. Prevalence and clinical course of viral upper respiratory tract infections in immunocompromised pediatric patients with malignancies or after hematopoietic stem cell transplantation. J Pediatr Hemato Oncol. 2012;34:442-9.

7. Rehder KJ, Wilson EA, Zimmerman KO, et al. Detection of Multiple respiratory viruses associated with mortality and severity of illness in children. Pediatr Crit Care Med. 2015;16:e201-6.

8. Feleszko W, Ruszczynski M, Zalewski BM. Non-specific immune stimulation in respiratory tract infections. Separating the wheat from the chaff. Paediatr Respir Rev. 2014;15:200-6.

9. Braido $F$, Tarantini $F$, Ghiglione $V$, et al. Bacterial lysate in the prevention of acute exacerbation of COPD and in respiratory recurrent infections. Int J Chron Obstruct Pulmon Dis. 2007:2:335-45.

10. Esposito S, Soto-Martinez ME, Feleszko W, et al. Nonspecific immunomodulators for recurrent respiratory tract infections, wheezing and asthma in children: a systematic review of mechanistic and clinical evidence. Curr Opin Allergy Clin Immunol. 2018; 18:198-209.

11. Rozy A, Chorostowska-Wynimko J. Bacterial immunostimulants-mechanism of action and clinical application in respiratory diseases. Pneumonol Alergol POI. 2008;76:353-9.

12. Kearney SC, Dziekiewicz M, Feleszko W. Immunoregulatory and immunostimulatory responses of bacterial lysates in respiratony infections and asthma. Ann Allergy Asthma Immunol. 2015:114:364-9.

13. Manolova $V$, Flace $A$, Jeandet $P$, et al. Biomarkers induced by the immunomodulatory bacterial extract $\mathrm{OM}-85$ : unique roles for Peyer's patches and intestinal epithelial cells. J Clin Cell Immunol. 2017:8:494.

14. Vaughn Williams EM, Millar JS, Campbell TJ. Electrophysiological effects of labetolol on rabbit atrial, ventricular and Purkinje cells, in normoxia and hypoxia. Cardiovasc Res. 1982;16:233-9.

15. Helin-Salmivaara A, Virtanen A, Vesalainen R, et al. NSAID use and the risk of hospitalization for first myocardial infarction in the general population: a nationwide case-control study from Finland. Eur Heart J. 2006;27:1657-63.

16. Lepist El, Gillies H, Smith W, et al. Evaluation of the endothelin receptor antagonists ambrisentan, bosentan, macitentan, and sitaxsentan as hepatobiliary transporter inhibitors and substrates in sandwich-cultured human hepatocytes. PLOS Substrates in sandwich

17. Dang AT, Pasquali C, Ludigs $K$, et al. OM- 85 is an immunomodulator of interferon-beta production and inflammasome activity. Sci Rep. 2017;7:43844.

18. Parola C, Salogni L, Vaira X, et al. Selective activation of human dendritic cells by OM- 85 through a NF-KB and MAPK dependen pathway. PLOS One. 2013;8:e82867

19. Luan $H$, Zhang $Q$, Wang $L$, et al. OM85-BV induced the productions of IL-1beta, IL-6, and TNF-alpha via TLR4- and TLR2-mediated ERK1/2/NF-kappaB pathway in RAW264.7 cells. J Interferon Cytokine Res. 2014;34:526-36.

20. Strickland DH, Judd S, Thomas JA, et al. Boosting airway T-regulatory cells by gastrointestinal stimulation as a strategy for asthma control. Mucosal Immunol. 2011; 4:43-52.

21. Roth M, Pasquali C, Stolz D, et al. Broncho Vaxom (OM-85) modulates rhinovirus docking proteins on human airway epithelial cells via Erk1/2 mitogen activated protein kinase and CAMP. PLOS One. 2017;12:e0188010.

22. Gao J, Gao X, Kong L. To investigate the prevention of OM-85 on bronchiectasis exacerbations (IPROBE) in chinese patients: study protocol for a randomized controlled trial. Trials. 2014;15:150.

23. Standardised Medical Dictionary for Regulatory Activities (MedDRA) Queries. Available at: www.meddra.org/ standardised-meddra-queries (accessed 3 February 2019).

24. Gutierrez-Tarango MD, Berber A. Safety and efficacy of two courses of $\mathrm{OM}-85 \mathrm{BV}$ in the prevention of respiratory tract infections in children during 12 months. Chest. 2001:119:1742-8.

25. Schaad UB, Mutterlein $\mathrm{R}$, Goffin $\mathrm{H}$, et al. Immunostimulation with $\mathrm{OM}-85$ in children with recurrent infections of the upper respiratory tract: a double-blind, placebo-controlled multicenter study. Chest. 2002;122:2042-9.

26. Bodemer C, Guillet G, Cambazard F, et al. Adjuvant treatment with the bacterial lysate (OM-85) improves management of atopic dermatitis: A randomized study. PLoS One. 2017;12:e0161555.

27. Tang H, Fang Z, Saborio GP, et al. Efficacy and safety of OM-85 in patients with chronic bronchitis and/or chronic obstructive pulmonary disease. Lung. 2015;193:513-9.

28. Orcel B, Delclaux B, Baud M, et al. Oral immunization with bacterial extracts for protection against acute bronchitis in elderly institutionalized patients with chronic bronchitis. Eur Respir J. 1994;7:446-52.

29. Schaad UB. OM-85 BV, an immunostimulant in pediatric recurrent respiratory tract infections: a systematic review. World J Pediatr. 2010;6:5-12.

30. Collet JP, Boissel JP. OM-85 BV: primary versus secondary prevention. Respiration. 1994;61 (Suppl 1):20-3.

31. Esposito S, Marchisio P, Prada E, et al. Impact of a mixed bacterial lysate (OM-85 BV) on the immunogenicity, safety and tolerability of inactivated influenza vaccine in children with recurrent respiratory tract infection. vaccine. 2014;32:2546-52

32. Lu Y, Li Y, Xu L, et al. Bacterial lysate increases the percentage of natural killer T cells in peripheral blood and alleviates asthma in children. Pharmacology. 2015;95:139-44.

33. Razi $\mathrm{CH}$, Harmanci $\mathrm{K}$, Abaci $\mathrm{A}$, et al. The immunostimulant OM-85 BV prevents wheezing attacks in preschool children. J Allergy Clin Immunol. 2010;126:763-9.

34. Chen ZG, Ji JZ, Li M, et al. [Immunoregulants improves the prognosis of infants with wheezing], Nan Fang Yi Ke Da Xue Xue Bao. 2007:27:1612-3.

35. Jara-Perez JV, Berber A. Primary prevention of acute respirator tract infections in children using a bacterial immunostimulant: a double-masked, placebo-controlled clinical trial. Clin Ther 2000;22:748-59.

36. Del-Rio-Navarro BE, Espinosa Rosales F, Flenady V, et al. Immunostimulants for preventing respiratory tract infection in children (Review). Evid Based Child Health. 2012;7:629-717.

37. Bitar MA, Saade R. The role of OM-85 BV (Broncho-Vaxom) in preventing recurrent acute tonsillitis in children. Int I Pediat Otorhinolaryngol. 2013;77:670-3.

38. Berber A, Del-Rio-Navarro B. Compilation and metaanalysis of randomized placebo-controlled clinical trials on the prevention of respiratory tract infections in children using immunostimulants. I Investig Allergol Clin Immunol. 2001;11:235-46.

39. Paupe J. Immunotherapy with an oral bacterial extract (OM-85 BV) for upper respiratory infections. Respiration. 1991;58:150-

40. Ravasio R. Economic analysis of the immunostimulant OM-85 for the prevention of paediatric recurrent upper respiratory tract infections. Global \& Regional Health Technology Assessment. 2015;2:135-42.

41. Anselmo-Lima WT, Sakano E, Tamashiro E, et al. Rhinosinusitis: evidence and experience. A summary. Braz I Otorhinolaryngo. 2015:81:8-18.

42. Ear-nose-throat Expert Committee. Expert consensus on the diagnosis, treatment and management of recurrent upper respiratory tract infection in children. Chinese J Practical Pediatrics. 2017:32:721-5.

43. Global Initiative for chronic Obstructive Lung Disease, Global strategy for the diagnosis, management, and prevention of chronic obstructive pulmonary disease. Available at: https:// goldcopd.org/wp-content/uploads/2017/11/GOLD-2018-v6.0FINAL-revised-20-Nov_WMS.pdf (accessed 3 February 2019).

44. Papi $\mathrm{A}$, Bellettato $\mathrm{CM}$, Braccioni F, et al. Infections and airway inflammation in chronic obstructive pulmonary disease severe exacerbations. Am J Respir Crit Care Med. 2006;173:1114-21.

45. Cazzola M, Capuano A, Rogliani P, et al. Bacterial lysates as a potentially effective approach in preventing acute exacerbation of COPD. Curr Opin Pharmacol. 2012;12:300-8.

46. Koatz AM, Coe NA, Ciceran A, et al. Clinical and immunological benefits of OM- 85 bacterial lysate in patients with allergic rhinitis, asthma, and COPD and recurrent respiratory infections. rhinitis, asthma, and COP

47. Collet JP, Shapiro P, Ernst P, et al. Effects of an immunostimulating agent on acute exacerbations and hospitalizations in patients with chronic obstructive pulmonary disease. The PARI-IS Study Steering Committee and Research Group. Prevention of Acute Respiratory Infection by an Immunostimulant. Am J Respir Crit Care Med. 1997;156:1719-24.

48. Li J, Zheng JP, Yuan JP, et al. Protective effect of a bacterial extract against acute exacerbation in patients with chronic bronchitis accompanied by chronic obstructive pulmonary disease. Chin Med J (Engl). 2004;117:828-34.

49. Soler M, Mutterlein R, Cozma G, et al. Double-blind study of $\mathrm{OM}-85$ in patients with chronic bronchitis or mild chronic obstructive pulmonary disease. Respiration. 2007;74:26-32

50. Pan $L$, Jiang $X G$, Guo J, et al. Effects of $O M-85$ BV in patients with chronic obstructive pulmonary disease: A systematic review and meta-analysis. J Clin Pharmacol. 2015:55:1086-92.

51. Dhamane AD, Moretz C, Zhou Y, et al. COPD exacerbation frequency and its association with health care resource utilization and costs. Int J Chron Obstruct Pulmon Dis. 2015;10:2609-18

52. Jain W, Allison R, Beck SJ, et al. Impact of an integrated disease management program in reducing exacerbations in patients with severe asthma and COPD. Respir Med. 2014;108:1794-800.

53. Fokkens WJ, Lund VJ, Mullol J, et al. EPOS 2012: European position paper on rhinosinusitis and nasal polyps 2012. A summary for otorhinolaryngologists. Rhinology. 2012;50:1-12

54. Dibildox J, Fernández AM, Butrón JLM, et al., Pan-American clinical practice guidelines for medical management of acute and chronic rhinosinusitis. Presented at the American Association of Otolaryngology - Head and Neck Surgery (AAOAssociation of Otolaryngology - Head and Neck Surgery (AAO-
HNSF) annual meeting. Available at: www.researchposters.com/ Posters/AAOHNSF/aa02012/SP512.pdf (accessed 3 February 2019).

55. EMEA, Technical report (EMEA/576176/2009). The bacterial challenge: time to react. Available at: https://ecdc.europa.eu/ sites/portal/files/media/en/publications/Publications/0909_ TER_The_Bacterial_Challenge_Time_to_React.pdf (accessed 20 September 2019).

56. European Centre for Disease Prevention and Control Antimicrobial resistance surveillance in Europe 2016. Available at: https://ecdc.europa.eu/en/publications-data/antimicrobialresistance-surveillance-europe-2016 (accessed 20 September 2019).

57. Williams MR, Greene G, Naik G, et al. Antibiotic prescribing quality for children in primary care: an observational study. Br J Gen Pract. 2018:68:e90-e6.

58. Man WH, de Steenhuijsen Piters WA, Bogaert D. The microbiota of the respiratory tract: gatekeeper to respiratory health. Nat Rev Microbiol. 2017;15:259-70.

59. Pletz MW, Tacconelli E, Welte T. [Antibiotic Stewardship 2.0 Individualization of therapy]. Internist (Berl). 2017;58: $657-65$.

60. Navarro S, Cossalter G, Chiavaroli C, et al. The oral administration of bacterial extracts prevents asthma via the recruitment of regulatory T cells to the airways. Mucosa Immunol. 2011;4:53-65.

61. Brown RL, Clarke TB. The regulation of host defences to infection by the microbiota. Immunology 2017:150:1-6. 